\title{
Visual screening for a potential evaluation of seismic vulnerability of historical building: Palace of the Dey (Citadel of Algiers)
}

\author{
A. Abdessemed-Foufa \\ Department of Architecture, Blida University, Algeria
}

\begin{abstract}
This work refers to the study carried out during 2006-07 on the Palace of the Dey in Algiers Citadel built during the $16^{\text {th }}$ and $19^{\text {th }}$ centuries. The study was undertaken during the management training of architects, archeologist and civil engineers of the Algerian Ministry of Culture by architects from Blida University in collaboration with IPOGEA, and Architects from Firenze and Bologna Universities. The stratigrafic study following the historical research has provided significant insight on the construction process. This information has been considered to investigate using visual screening the possible link between construction and existing damages. This example shows insight on the construction process, historical and recent earthquakes and bombing causeddamages, and later man-caused alterations. The existing damages and deformations accentuate seismic vulnerability of this monument as Algiers is located in the most important area of seismic risk in Algeria.

Keywords: existing damage, construction process, Palace of the Dey, Citadel of Algiers, Casbah of Algiers, Algeria.
\end{abstract}

\section{Introduction}

This study was undertaken in close cooperation between architects from Algerian university (Blida), Italian architects from Bologna and Firenze Universities and IPOGEA of Matera for training architects, civil engineers and archeologists of the Algerian Ministry of Culture (htpp://www.IPOGEA.org [1]. The project was untitled "Initiative of training for the recovery and the valorization of the Casbah of Algiers according to the traditional techniques and their reuse in an innovating way". The building analyzed in this study is an 
Ottoman monument "the Palace of the Dey" of Algiers. It shows common architectural feature of Arab Islamic palaces. A central square courtyard surrounded by galleries. Detailed research on available historical sources does not enable us to determine all the construction process. But it was possible following an investigation of stratigraphic reading to identify the process of construction and the imprint of events (constructive typology, architectural alterations and earthquake). Based on historic documentations information's and stratigraphic reading, a sequential structural analysis and pathology study have been developed as a preliminary seismic vulnerability evaluation. An essential issue of the diagnosis lays in the distinction of damage related to active phenomena, historical actions (as fire, bombing, lack of maintenances and inadequate restorations) and natural hazard (as earthquake and soil settlements).

\section{Description of the palace}

Since the Ottoman occupation of Algiers by Barbarous Brothers, the reinforcement of the wall of the city, the gates and the fortifications was started. From the proclamation of Arudj's authority, he started the rebuild of the citadel some $300 \mathrm{~m}$ higher than the oldest one. It was located towards the more culminating point of the city (De Haedo [2]). The citadel was constructed around 1552-1572/73 (Missoum [3]). The first illustration which exists was drawn by a Spanish prisoner in 1563 (Braudel [4]). On that picture the citadel appears in the top of the medina and is separated from all districts (Figure 1).

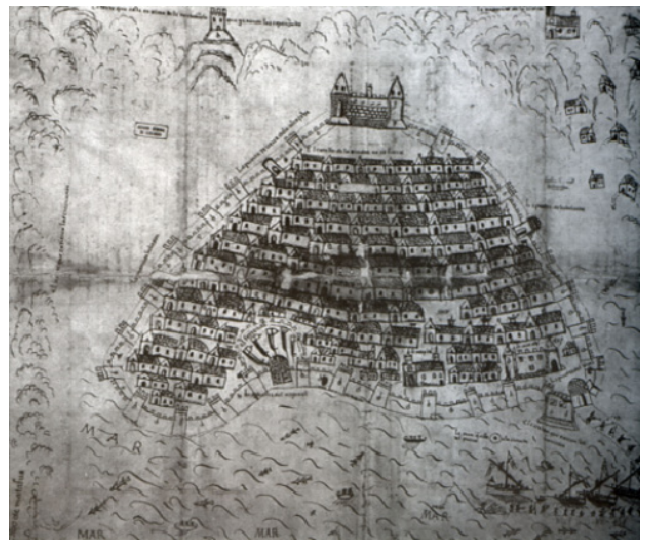

Figure 1: Algiers drawn by a prisoner in 1563 (Braudel [4]).

The citadel probably contained, at the beginning, a walk way, the powder keg and the janissaries diwan's room. There is no any date of construction of the several buildings such as the palace of the Dey its mosque and hammam, and the palace of the Beys which have been constructed over a long period (Figures 2(a) and (b)). During the Ottoman Regency no Dey of Algiers resided at the Citadel. In 1817, the Dey Ali Khudja left the official residence Al Djanina located in the 

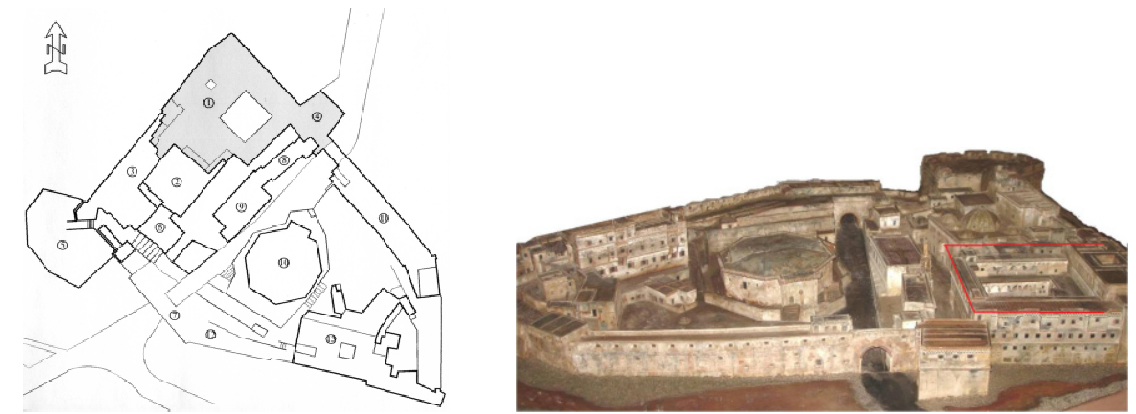

Figure 2: (a) Overall plan of the citadel and the palace in grey (Casbah [5]), (b) global view of the citadel (maquette).

lower part of the city to find refuge in the Citadel. No building had been designed to accommodate the sovereign and his court. At the beginning they leave in this barracks of janissaries. It seems that this whole monument was built from 1817 to 1830 . According to historical sources it is known that only one Dey; in fact Ali Khudja; lived at the palace. Thus various installations inside the palace were made such as the harem, the apartments of the Dey, the music room, the hammam and kitchen. The palace of the Dey is occupying the north-eastern angle of the citadel. Its form is a rectangle with a large interior court or patio (Figure 3) (Casbah [5]). In the south-eastern angle is located the advanced entry called sqifa. The whole building is heterogeneous because of its different strata and periods of construction. The palace constitutes the greatest part of the citadel considering its volume and surface. The external walls of the north-east belong to the ramparts. The whole building forms an irregular rectangle surrounded by four galleries. The north-west wings of this building rises on three levels while the south-east wings raise two levels (Figures 4(a) and 4(b)).

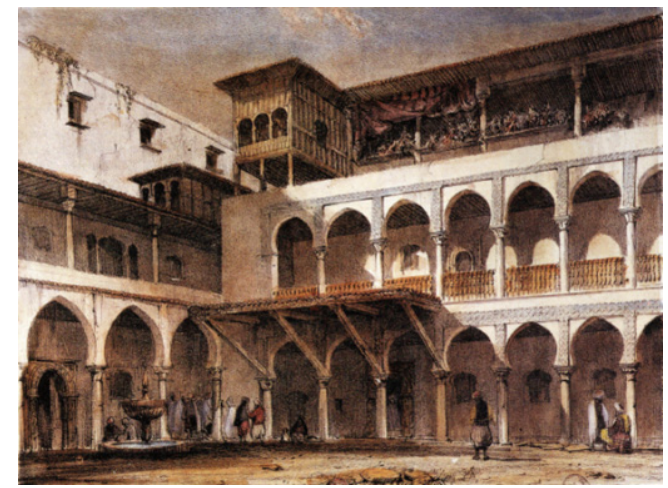

Figure 3: $\quad$ Lithography of the patio (Lessore and Wyld 1833). 


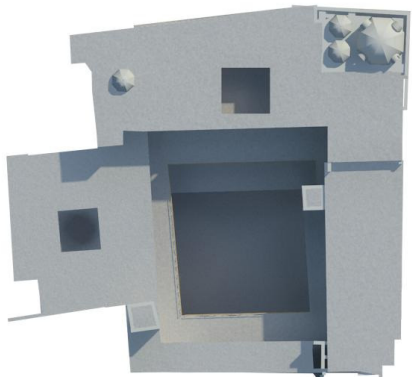

(a)

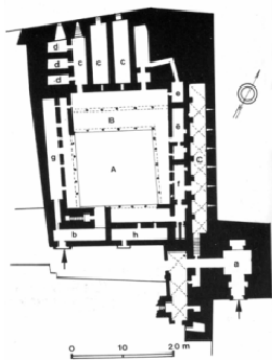

(c)

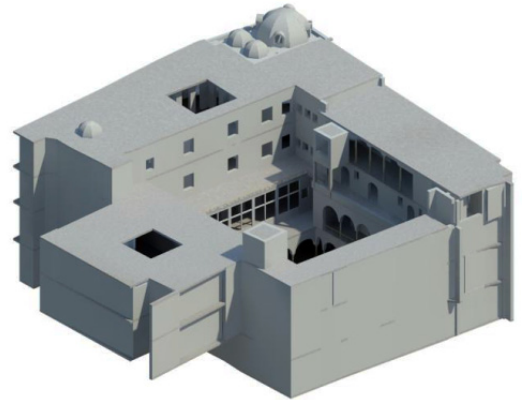

(b)

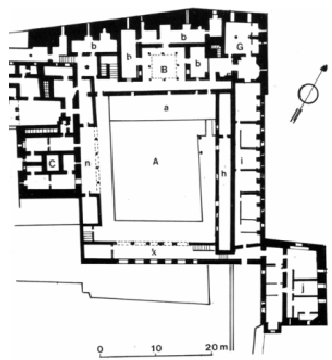

(d)

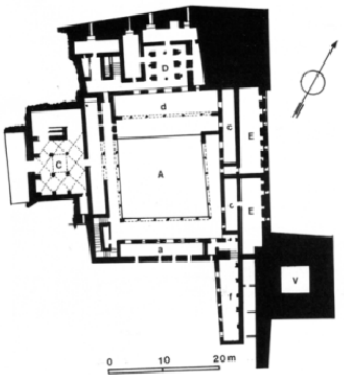

(e)

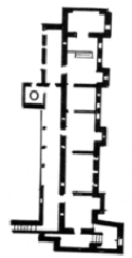

(f)

Figure 4: $\quad$ (a) Plan of mass, (b) 3D view (Abdessemed-Foufa [7]), (c) ground floor, (d) first floor (Golvin [6]), (e) second floor, (f) third floor with its attic storey (Golvin [6]).

\subsection{The ground floor}

A part the patio and the four galleries, the ground floor contains several spaces surrounding them. In the north-western part, the gallery is duplicated by a second one. Just after let us find three oblong spaces covered by vaults: these are the treasure. There is only one gallery in the north-eastern part, behind which are located two series of joint spaces. In the first line are four rectangular spaces 
which represent magazines. The second line is a long covered of cross vaults space with bored loopholes and which is called dahlīz. The two other southeastern and south-western parts have each only one gallery, behind which are rectangular spaces covered by wooden floors. These are also magazines (Figure 4(c)) (Golvin [6]).

\subsection{The first floor}

We can find four galleries surrounding the central space. The Harem is built on two floors; it extends from the $1^{\text {st }}$ to $2^{\text {nd }}$ level and is located in the north-western part as the music room which is located in the north-eastern corner of the palace. The library is in the north-eastern part while the kitchen is located in the southwestern parts. The whole of this storey is covered by wooden floors except the music room, and kitchen which are covered respectively by an octagonal dome and cross vaults (Figure 4(d)) (Golvin [6]).

\subsection{The second floor}

On the second floor we find three galleries located in the south-eastern, south and south-western parts. The second floor of the Harem and the apartment of the Dey are located in the north-western and in the north-eastern part. The hammam and the residence of the employed personnel are both in the south-western part. There is no building in the South-Eastern part but only a gallery (Figure 4(e)). This storey is covered by wooden floors except the hammam which is covered by cross vaults (Golvin [6]).

\subsection{The third floor}

Between the $3^{\text {rd }}$ level and terraces of the north-eastern parts, we can found a false storey with very low ceiling. This area is divided in several small tiny rooms organized as a view-point directed towards the court. These later are covered by a wooden roof maintained by three columns supporting wooden plat bands. On this level is located an attic storey made of wood which is improperly called "Pavillon du coup de l'évantail" (Figure 4(f)) (Golvin [6]).

\section{Construction process through stratigraphic analysis}

\subsection{Positive and negative interfaces}

Construction of the Dey palace began on 1596-1599 as a janissary citadel. It involved, in the first place, the construction of the full perimeter, including magazines surrounding the patio, a walk way, the powder keg and the janissaries' diwan's room. This study on the palace showed that several actions of construction, demolition and rebuilding took place successively in time. Unfortunately, we do not have any dating. Only the materials and the techniques of construction have reveals these actions. The architectural stratification applied 
to the patio of the palace showed that constructive strata are characterized by negative and positive actions of construction and of transformation's actions which modified what existed. The periods of use which interpose between the successive constructive phases express by entropic degradations due to the use of the palace, as well as natural deterioration due mainly to the earthquakes and to the action of the atmospheric agents (marine salt). The architectural stratification thus appeared by layers; which represent different remanent parts of the various founder's shares which occurred throughout the history of this building as well as negative interfaces which are the demolitions traces. The example of the Southeastern part of the ground floor represents first of all the positive interfaces where the second line of the gallery was closed to create various spaces. Thus the columns were built. The walls have openings (doors and windows). Secondly, there were negative interfaces because there were demolitions of the walls to create openings then positive interfaces representing the rebuilding of these same interfaces (Figures $5 \mathrm{a}$ and $5 \mathrm{~b}$ ).
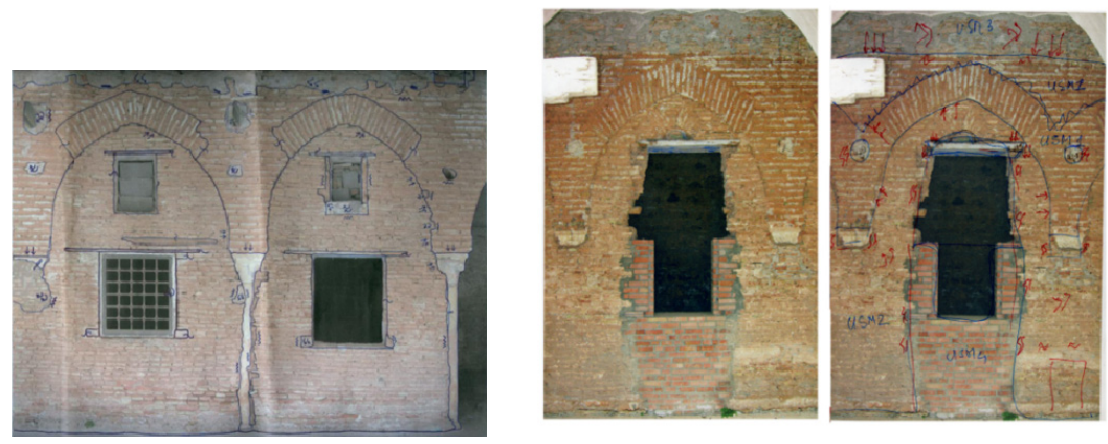

Figure 5: (a) and (b) south-eastern frontage with various layers and interfaces (Abdessemed-Foufa [7]).

While the south-eastern face underwent many phases of construction. On the part of this patio's frontage (gallery wall), negative interfaces due to the demolitions and positive interfaces due to the rebuilding of these same negative interfaces are visible. The architectural layers for this wall are laid out in various directions. Thus appears according to this following stratigraphic study that the interior line of arcades was built. This would tend to conclude that this part of the ground floor was like its opposite frontage. In such way there were initially two galleries on both sides (Figure 6).

The music room is built on the remainder of the city-walls. It was practically a symmetrical space with a large cupola in the center and four small cupolas of share and others, two existing and two others demolished. It would deem that the continuity of the blocks was destroyed following the demolition of the citywalls. Positive interfaces due to the rebuilding of the wall are visible. There remain two opposite columns built like witnesses. Concerning the stairwell, the presence of layers of plaster and painting inside of the crack supposes that the external wall was built by backing. Thus it rests on the wall. This implies that the 


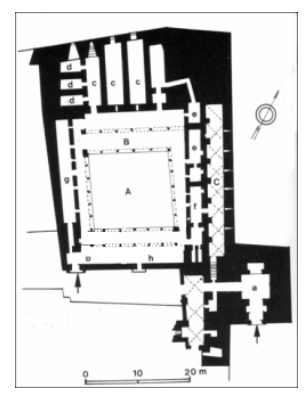

Figure 6: Initial ground floor (restitution by Abdessemed-Foufa [7]).

construction of the stairwell's external wall is posterior at the origin of the patio. This also implies that all the partition relating to the kitchens, hammam was built in the second time, probably following the arrival of the Dey with his court.

\subsection{Materials and constructive typology}

The stratigraphic units are characterized by the used materials. In this case we have traditional bricks masonry of $3 \times 12 \times 20 \mathrm{~cm}$ size bounded by lime and earth mortar having $3 \mathrm{~cm}$ thickness. Beside the layer of filling is built by industrialized bricks having $5 \times 11 \times 22 \mathrm{~cm}$ size and are bound by a cement mortar of $1 \mathrm{~cm}$ thickness. If we consider, the northern frontage, the stratigraphic study showed us that the interventions are tinier and that this part of the building comprises only positive interfaces which represent the layers of repair. The southern and western frontages underwent heightening which sheltered respectively the Harem and the private apartments of the Dey. The constructive typologies of the Dey's Palace are various. Some walls as external are in emplecton masonry using bricks and lime mortar in the two faces of the walls; their thickness varies from $1.50 \mathrm{~m}$ to $3.00 \mathrm{~m}$. The other walls of interiors are load-bearing walls made of brick masonry and laid with a lime mortar; their thickness varies from $0.30 \mathrm{~m}$ to $0.60 \mathrm{~m}$. Since the 1716 earthquake some others techniques were introduced in order to resist the seismic loads. The load-bearing walls were reinforced by wooden logs laid out in all the thickness of the wall (Abdessemed-Foufa [7]).

\section{Existing damage}

The Palace of the Dey presents several existing damages distributed through all places of this monument. However this study will be concentrated only on two areas. The two diametrically opposite angles located at the north-western and north-eastern part of the palace because of their remarkable historical pathologies. These two angles in the Dey palace which present static weakness are:

- The stairwell located in the south-western angle (Figures 7 and 8) (PKZ [8]).

- The music room located in the opposite angle i.e. north-eastern (Figures 7 and 9(a)-(d)). 
In this analysis we recorded five different types of alterations, visible in both parts of the building and are highlighted and discussed:

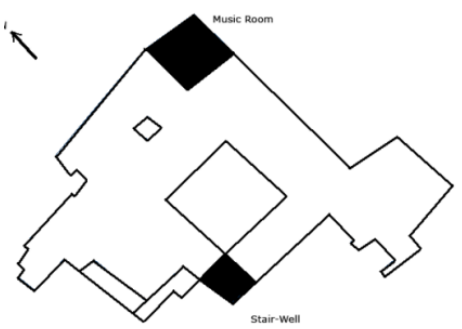

Figure 7: $\quad$ Stairwell and music room location (Abdessemed-Foufa [7]).
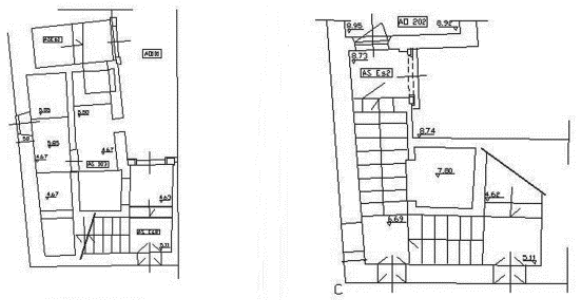

Figure 8: $\quad$ Stairwell plans (PKZ [8]).

\subsection{Cracking in walls and façade}

Cracks exist in walls of both spaces. Vertical cracks have developed across the bricks masonry walls extending to all their depth and can also be recognized in the exterior. The cracks in the music room are due to the ageing of materials, to the highest compression of cupola, the excessive loads and effects of the historical and recent earthquakes. In the stairwell the orthogonal walls are not connected that induced the vertical cracks which are due to the heightening of the floors which were constructed without taking account of any state of art to build (absence of chaining) (Figure 10).

\subsection{Cracking in floor}

Horizontal cracks have developed across the wooden floor and the marble staircases. These cracks are due to the exercise of a bending stress introduced by an overload (Figures 11(a) and 11(b)). 


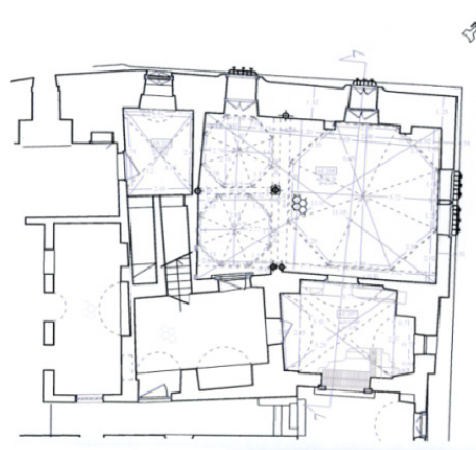

(a)

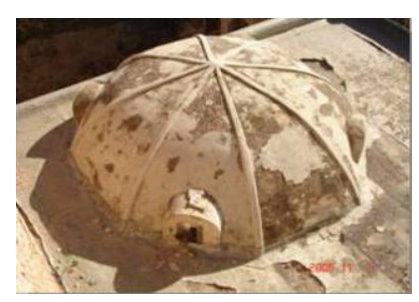

(c)

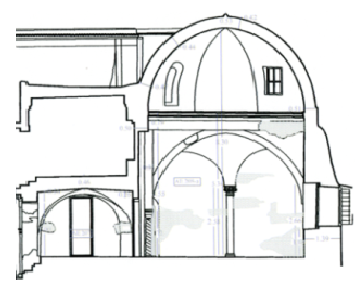

(b)

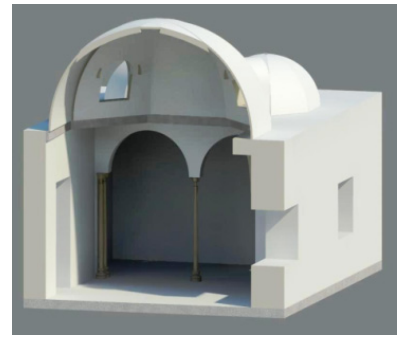

(d)

Figure 9: (a) and (b) music room plan, section (PKZ [8]), (c) view, (d) 3D block restitution (Abdessemed-Foufa [7]).

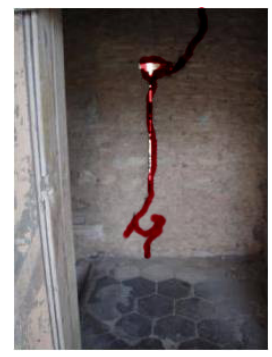

(a)

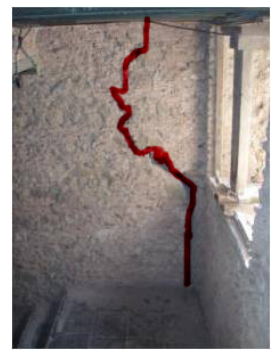

(b)

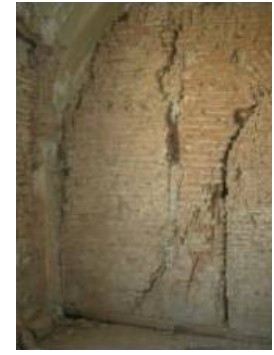

(c)

Figure 10: (a), (b) vertical cracks in the stairwell and (c) in the music room (Abdessemed-Foufa [7]). 


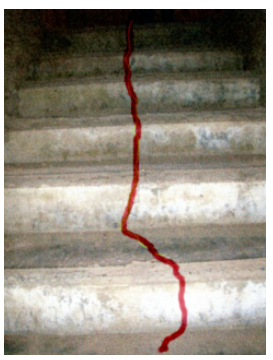

(a)

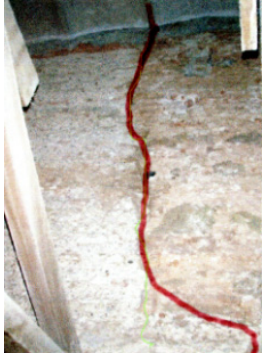

(b)

Figure 11: (a) Horizontal cracks in stairs, (b) horizontal cracks in floors (Abdessemed-Foufa [7]).

\subsection{Cracking in vault}

In the cross vault of the music room in north-eastern angle, cracks have developed following the keystone of the transverse sides (Figure 12). These cracks are due to the horizontal displacement of abutment.

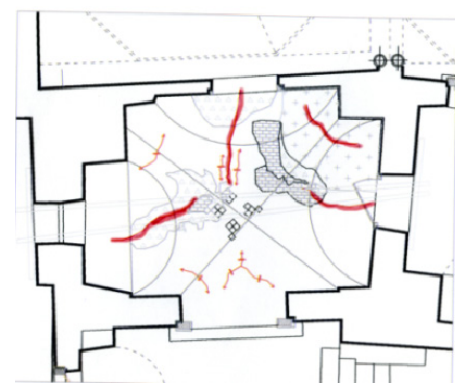

Figure 12: Cracks in the cross vault.

\subsection{Cracking in cupola}

In the octagonal cupola of the music room cracks have developed following the transverse sides. These cracks are principally due to the horizontal displacement of abutment and also to the decompression generated by the displacement of lateral walls (Figures 13(a) and 13(b)). 


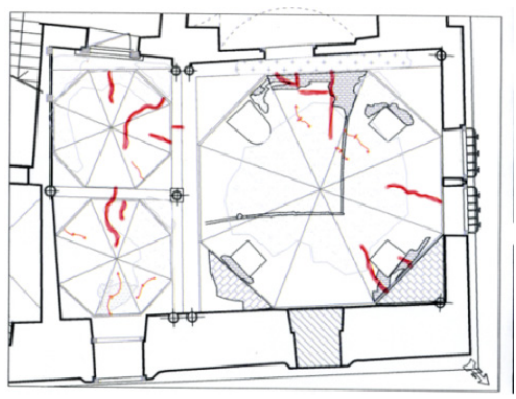

(a)
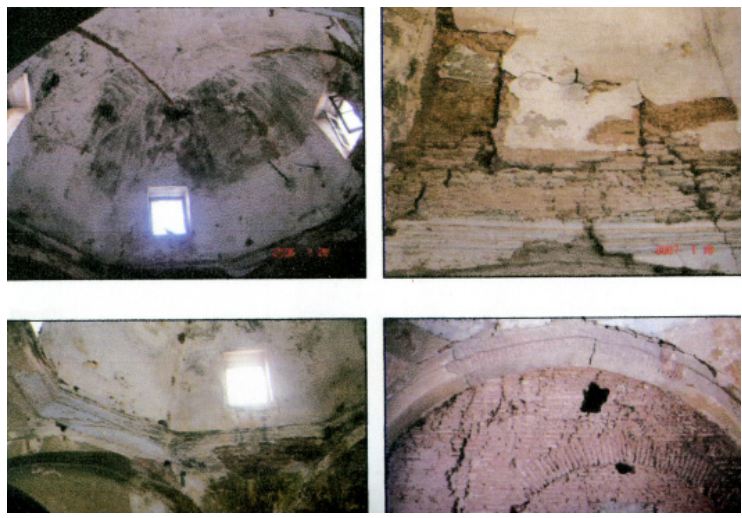

(b)

Figure 13: (a) Cracks in the cupola, (b) different cracks in the music room (Abdessemed-Foufa [7]).

\subsection{Cracking in arches}

Arches carrying the cross vault and the octagonal cupola are fissured at the level of their keystone because of the highest compression of these cover built and of the weakness of the abutments. Lateral abutments of arches are fissured because of their weakness (Brenda [9]; De Cesaris [10]).

\section{Construction process and damage}

The Palace of the Dey was built on the janissaries' barracks. The various phases of constructions are not well known but the damage observed on the spot showed that the stairwell located at the south-western angle was built during a later phase. The external orthogonal walls are not chains between them. The south frontage wall is simply leant against the orthogonal one. The presence of final layer of mortar is still visible until today. This important crack was created through time and later the effects of earthquakes and that one of 23/05/2003 accentuated its state which today cut the south-western wall of the stairwell 
upwards. The cracks observed on the marble stairs and wooden roofs are due to excessive loads caused on one hand by the soldiers during colonization (18301962), on the other hand by undue occupying which have squat the places after independence (1963-1979). In addition to that, the wooden beams; acting as elements of wind-bracing; inserted in the external wall of the stairwell and on the wall of the sqifa were divided. This created a displacement and a dextral deformation of external wall of the secondary entry hall. This weakened this angle and increased its vulnerability. During the French colonization, the citywall of which the thickness reached more than $1 \mathrm{~m} 50$ and which leant against the music room was destroyed by the French army engineers during the great transformation of Algiers city (Figure 14). This external wall acted initially as wind-bracing to this massive block of constructions (north-east of the palace). Since its demolition, the angle is in a constant instability whence the appearance of these various disorders which amplified its vulnerability.

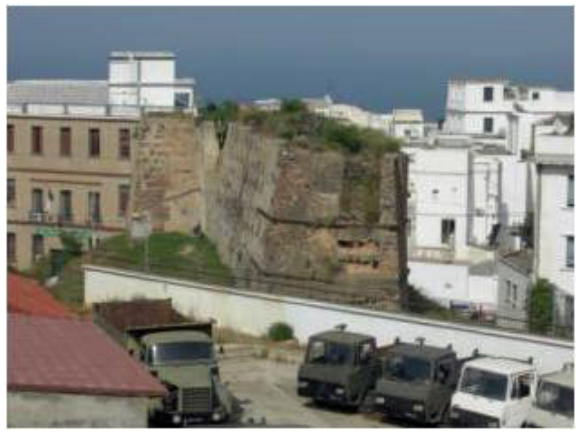

Figure 14: External view since the room of music of the reminder city wall (Abdessemed-Foufa [7]).

\section{Conclusion}

As shown in the two angles investigated using visual screening, the construction process may have significant influence on the initial condition of construction. Some of alterations (large deformation in walls, damage on cupola and crossvault) might be attributed to the destruction process which belongs to the historical evolution of the Palace and the city of Algiers. Later entropic actions (repairs) should be included as a part of deterioration. The visual screening unable we to establish the cracking frame of the two diametrically opposite angles which present the slightness of the Palace. These damages of a very important degree will produce a possible destruction of these various parts of the palace if a moderate earthquake would occur in Algiers. Historical documentation may provide meaningful information on the construction process and even on different actions of repairs and demolition. The detailed visual screening may also provide important clues on the way the Palace was built, the deteriorations caused by the natural risks, the entropic actions such as repairs, constructions as well as the demolitions. The experience of training of architects 
and engineers from the ministry of culture in collaboration with IPOGEA institution, lecturers from Florence University and lecturers of the University of Blida between 2006 and 2007 made it possible to the students to be confronted at technological advances as regards to the preservation of the historical built heritage. Knowing that in Algeria our experience in restoration is very recent. Indeed it is only starting from the promulgation of the 98-04 law on preservation of historical heritage and its text of application since 2006 that qualified architects in monuments and historic sites practice as architects 'restorers. During this training the use of instruments of diagnosis not related in this paper helped all Algerian staff to apprehend the problems of static stability not only using a visual screening but also while using instrumental measurements. It does not remain that the first diagnostic is always visual.

\section{References}

[1] University "Saad Dahleb" of Blida and IPOGEA. Training courses: "Initiative of training for the recovery and the valorization of the Casbah of Algiers according to the traditional techniques and their reuse in an innovating way". Valorizzazione della Casbah Di Algeri. 2006-2007. htpp://www.IPOGEA.org

[2] De Haedo, D., Topographia general de Argel. Translatted by Monnerreau, D and Berbrugger, Retranscribed by Rebahi, A., G.A.L: Algiers, pp.24-26, 2004.

[3] Missoum, S., Alger à l'époque Ottomane. La médina et la maison traditionnelle. INAS: Algiers, p.22, 2003.

[4] Braudel, P., La Méditerranée et le monde méditerranéen à l'époque de Philippe II. Colin: Paris, pp.192-193, 1966.

[5] Casbah, Architecture et Urbanisme., Catalog of exposure of the $30^{\text {th }}$ anniversary of the Algeria armed struggle release. OREF-GAM : Bruxelles, p.73, 1984.

[6] Golvin, L., Palais et demeures d'Alger. INAS : Algiers, pp. 24-26, 2003.

[7] Abdessemed-Foufa, A, A., Contribution for a catalogue of earthquake resistant traditional techniques in Northern Africa: the case of the Casbah of Algiers (Algeria). European Earthquake Engineering 2(4), pp.23-39, 2005.

[8] PKZ., Project of the Citadel Restoration, Graphic documentation: Plan, section and façade, 1980.

[9] Brenda, P., Bâtiments en maçonnerie. Analyse des déséquilibres statiques et techniques de consolidation. Centro Annalisi Sociale Progetti: Rome, pp.39-51, 1993.

[10] De Cesaris, F., La restauration statique. L'intervention de consolidation statique comme choix de projet entre les nécessités techniques et les impératives de la conservation. Centro Annalisi Sociale Progetti: Rome, pp.33-39, 1996. 